\title{
The Effect of Bariatric Surgery versus Intensive Medical Care on Prevention of Microalbuminuria in Patients with Type 2 Diabetes: 3 Year Experience of a Prospective Study
}

\author{
Amin Soliman ${ }^{1}$, Haythum Soliman ${ }^{1}$, Mervat Naguib ${ }^{1,2 *}$ \\ ${ }^{1}$ Department of Internal Medicine, Faculty of Medicine, Kasr Al-Ainy Hospital, Cairo University, Cairo, Egypt; ${ }^{2}$ Diabetes and \\ Endocrinology Unite, Cairo, Egypt
}

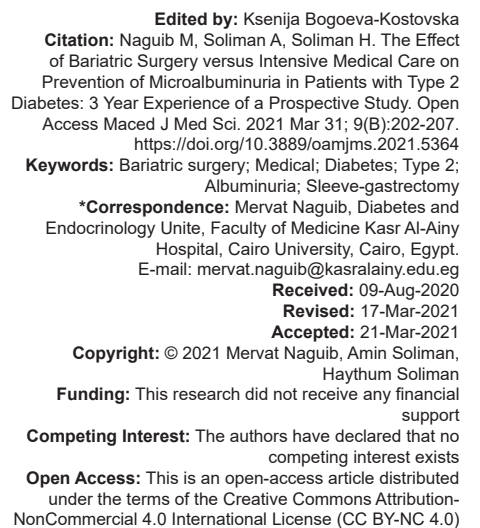

Edited by: Ksenija Bogoeva-Kostovsk of Bariatric Surgery versus Intensive Medical Care on abetes: 3 Year Experience of a Prospective Study Ope Access Maced J Med Sci. 2021 Mar 31; 9(B):202-207. Unite, Faculty of Medicine Kasr Al-Ainy guib@kasralainy.edu.eg Revised: $17-M a r-2021$ guib, Amin Soliman Haythum Soliman

Funding: This research did not receive any financial Competing Interest: The authors have declared that $\mathrm{n}$ Open Access: This is an open-access article distribute NonCommercial 4.0 International License (CC BY-NC 4.0)

\begin{abstract}
BACKGROUND: Bariatric surgery could improve diabetic kidney disease; however, the effect of surgery versus medical therapy on renal out comes needs further evaluation.

AIM: The aim of the study was to investigate the effect of sleeve-gastrectomy versus intensive medical therapy on the prevention of albuminuria in patients with Type 2 diabetes mellitus (T2DM)

METHODS: This is a prospective study of 33 patients with T2DM undergoing sleeve gastrectomy matched for age sex, and duration of diabetes to 64 medically treated patients. Urinary albumin/creatinine ratio (UACR) was assessed before and 3-year after intervention.

RESULTS: At baseline, there was no significant difference between surgical and medical group regarding body mass index (BMI), blood pressure, Hemoglobin A1c $(\mathrm{HbA} 1 \mathrm{c})$, or uACR. After 3 years of interventions the mean BMI $\left(\mathrm{kg} / \mathrm{m}^{2}\right)$ and $\mathrm{HbA} 1 \mathrm{c}(\%)$ became significantly lower in the surgical group compared to medical group. Although mean uACR $(\mathrm{g} / \mathrm{mg})$ increased after interventions compared to its levels before interventions in both surgical (11.7 $\pm 4.8 \mathrm{vs} .18 .2$ $\pm 5.9) \mathrm{g} / \mathrm{mg}$ and medical $(13.4 \pm 4.5 \mathrm{vs} .17 .1 \pm 6) \mathrm{g} / \mathrm{mg}$ groups, albuminuria developed in only three surgical patients and two medical patients $(p>0.05)$

CONCLUSION: Although bariatric surgery is associated with more reduction in body weight and better glycemic control than intensive medical therapy, sleeve-gastrectomy may not be superior to intensive medical care in prevention of microalbuminuria in patients with T2DM.
\end{abstract}

\section{Introduction}

Type 2 diabetes mellitus (T2DM) is a major health problem worldwide [1]. The incidence of T2DM has increased rapidly in the past few decades, according to the International Diabetes Federation, Egypt is in the world $8^{\text {th }}$ place in the of incidence of diabetes and its prevalence is up to $9.3 \%$ of population and this number is expected to rise due to the rapid increase in the prevalence of obesity [2].

Diabetic kidney disease (DKD) is one of the major microvascular complications of T2DM and affects about $20-30 \%$ of patients with T2DM [3]. Moreover, $\mathrm{DKD}$ is a leading cause of end-stage renal disease (ESRD) with high morbidity and mortality [4].

Obesity is a leading cause of T2DM [5]. Furthermore, obesity is linked to the development of chronic kidney disease [6]. Different researches showed an association between obesity and different parameters of renal damage in patients with diabetes [7], [8].

Indeed, long-term glycemic control reduces the risk of ESRD [9]. Furthermore, weight reduction can help in control of blood pressure, improves insulin sensitivity and is associated with better glycemic control [10]. The previous studies showed that weight loss can improve or preserve renal function among obese subjects with or without T2DM [11].

Weight reduction and glycemic control could be obtained either by metabolic surgery or intensive medical treatment. However, bariatric surgery is not without complication and medications and lifestyle intervention are difficult.

Surgical weight loss was found to normalize glomerular hyperfiltration and decrease albumin excretion rate in morbidly obese persons [12], and dietary weight loss was associated with beneficial effects on albuminuria, proteinuria, and the decline in the estimated glomerular filtration rate (eGFR) in patients with pre-existing CKD [13].

Although recent studies have shown that bariatric surgery significantly improve albuminuria in subjects with diabetes, these studies were limited by being retrospective, small sample size or short-term one [12], [14]. To the best of our knowledge, no study primarily investigated the effect of medical care versus 
bariatric surgery in prevention of DKD in obese subjects with diabetes and normoalbuminuria. Thus, the aim of this 3-year prospective study was to compare the impact of sleeve-gastrectomy versus intensive medical therapy on the development of albuminuria in originally normoalbuminuric obese patients with T2DM.

\section{Materials and Methods}

\section{Study design}

This study was a prospective randomized study conducted in a tertiary care referral hospital between January 2016 and January 2019. We assigned 97 eligible patients with T2DM to undergo intensive medical therapy or sleeve-gastrectomy.

\section{Subjects and methods}

Patients between 20 and 60 years with diagnosis of T2DM (Hemoglobin A1c [HbA1c] $>7.0 \%$ ), and a body mass index (BMI) above 27 were eligible for the inclusion criteria. Patients were excluded if they had urinary albumin/creatinine ratio (uACR) $>30 \mathrm{mg} / \mathrm{g}$ or eGFR $<60 \mathrm{~mL} / \mathrm{min} / 1.73 \mathrm{~m}^{2}$ or undergone previous bariatric surgery or other complicated abdominal procedures or had inadequately controlled medical or psychiatric disorders.

All patients provided informed consent to participate in this study. The study protocol and procedures conform to the ethical guidelines of the 1975 Declaration of Helsinki.

All patients were subjected to thorough medical evaluation including determination of age, gender, duration of diabetes, history of antidiabetic medications, and BMI calculation. Intensive medical therapy comprising lifestyle modification, weight reduction, and frequent home glucose monitoring was provided to all participants as perADA standards of care [15], [16]. The patients were evaluated by diabetologist and dietitian every 3 months. The goal of medical management was $\mathrm{HbA} 1 \mathrm{c} 6.0 \%$ (63.9 $\mathrm{mmol} / \mathrm{mol})$ or less or development of recurrent sever hypoglycemia. For all patients the following targets have been provided: Systolic blood pressure (SBP), $130 \mathrm{~mm} \mathrm{Hg}$ or less; diastolic blood pressure (DBP), 80 $\mathrm{mm} \mathrm{Hg}$ or less; and low-density lipoprotein cholesterol, $100 \mathrm{mg} / \mathrm{dl}$ or less. Sleeve gastrectomy was performed laparoscopically to decreases gastric volume by $75 \%$. After sleeve gastrectomy patients were followed up by diabetologist and dietitian every 3 months.

Data on the following parameters BMI, antidiabetic medications, HbA1c, eGFR as estimated by modified Modification of Diet in Renal Disease formula [17], and UACR were collected at the time of surgery and annually for 3 years post-surgery.

\section{Statistical analysis}

Data were entered and statistically analyzed on the Statistical Package for the Social Science Software program, version 25 (IBM SPSS Statistics for Windows, Version 25.0. Armonk, NY: IBM Corp.). Data were presented using mean and standard deviation or median with interquartile range for quantitative variables and frequency and percentage for qualitative ones. Comparison between groups for qualitative variables was performed using Chi-square or Fisher's exact tests while for quantitative variables the comparison was conducted using Mann-Whitney test. $p \leq 0.05$ was considered statistically significant.

\section{Results}

The study included 97 patients with T2DM, $51.5 \%$ of them were females and $48.5 \%$ were males. Most of our patients were between 45 and 60 years. The mean duration of diabetes in the sleeve-gastrectomy group and medical-therapy group was $6.8( \pm 2.7)$ years and $6.3( \pm 2.6)$ years, respectively.

Table 1: Clinical and laboratory data of surgical group before and 3-year after surgery

\begin{tabular}{|c|c|c|c|}
\hline Data (Mean \pm SD) & $\begin{array}{l}\text { Pre-operative } \\
(n=33)\end{array}$ & $\begin{array}{l}\text { 3-year post sleeve-gastrectomy } \\
(n=33)\end{array}$ & $\mathrm{p}$-value \\
\hline BMI $\left(\mathrm{kg} / \mathrm{m}^{2}\right)$ & $35.7 \pm 1.9$ & $27.2 \pm 1$ & $<0.0001$ \\
\hline $\mathrm{SBP}(\mathrm{mmHg})$ & $141.5 \pm 8.1$ & $127.7 \pm 6.4$ & 0.000 \\
\hline $\mathrm{DBP}(\mathrm{mmHg})$ & $86.4 \pm 5.7$ & $81.4 \pm 3.5$ & 0.000 \\
\hline $\mathrm{HbA} 1 \mathrm{c}(\%, \mathrm{mmoL} / \mathrm{moL})$ & $8.9 \pm 0.5(73.8)$ & $7.3 \pm 0.3(56)$ & $<0.0001$ \\
\hline eGFR $\left(\mathrm{mL} / \mathrm{min} / 1.73 \mathrm{~m}^{2}\right)$ & $100.3 \pm 12.5$ & $102.2 \pm 7.6$ & 0.458 \\
\hline $\mathrm{UACR}(\mathrm{mg} / \mathrm{g})$ & $11.7 \pm 4.8$ & $18.2 \pm 5.9$ & $p<0.0001$ \\
\hline $\begin{array}{l}\text { No. of patients with } \\
\text { albuminuria }\end{array}$ & None & 3 & 0.238 \\
\hline
\end{tabular}

After 3 years of interventions, there was significant reduction in BMI, SBP, DBP, and $\mathrm{HbA} 1 \mathrm{c}$ in both surgical (Table 1) and medical group (Table 2).

Table 2: Clinical and laboratory data of medical group before and 3-year after therapy

\begin{tabular}{llll}
\hline Data Mean \pm SD & $\begin{array}{l}\text { Baseline } \\
(\mathrm{n}=64)\end{array}$ & $\begin{array}{l}\text { 3-year post-intensive } \\
\text { medical therapy }(\mathrm{n}=64)\end{array}$ & $\mathrm{p}$-value \\
\hline $\mathrm{BMI}\left(\mathrm{kg} / \mathrm{m}^{2}\right)$ & $36.2 \pm 1.5$ & $33.7 \pm 5$ & $<0.0001$ \\
$\mathrm{SBP}(\mathrm{mmHg})$ & $144.5 \pm 8.1$ & $130.3 \pm 6.1$ & 0.000 \\
$\mathrm{DBP}(\mathrm{mmHg})$ & $88.7 \pm 5.3$ & $83 \pm 4.1$ & 0.000 \\
$\mathrm{HbA1c}(\%, \mathrm{mmoL} / \mathrm{moL})$ & $8.8 \pm 0.7) 73)$ & $8.2 \pm 0.4(66)$ & $\mathrm{p}<0.0001$ \\
eGFR $\left(\mathrm{mL} / \mathrm{min} / 1.73 \mathrm{~m}^{2}\right)$ & $102.6 \pm 9.2$ & $103.5 \pm 10.5$ & $\mathrm{p}=0.6069$ \\
uACR $(\mathrm{mg} / \mathrm{g})$ & $13.4 \pm 4.5$ & $17.1 \pm 6$ & $\mathrm{p}=0.0001$ \\
No. of patients with albuminuria & None & 2 & 0.496 \\
\hline BP: Blood pressure, eGFR: Estimated glomerular filtration rate, HbA1c: Hemoglobin A1c, uACR: Urine \\
albumin-to-creatinine ratio. ${ }^{*} \mathrm{p}<0.05$. BMl: Body mass index, SBP: Systolic blood pressure, DBP: Diastolic \\
blood pressure.
\end{tabular}

At baseline, there was no statistically significant difference in the BMI between surgical and medical group. However, at 1 year follow-up, the surgical cases had lower BMI than the medical cases and mean BMI decreased from $35.7( \pm 1.9) \mathrm{kg} / \mathrm{m}^{2}$ at baseline to $26.2( \pm 1.1) \mathrm{kg} / \mathrm{m}^{2}$ in sleeve gastrectomy group and from $36.2( \pm 1.5) \mathrm{kg} / \mathrm{m}^{2}$ to $32.8( \pm 5) \mathrm{kg} / \mathrm{m}^{2}$ in the medical-therapy group. Although there was mild increase in the BMl in the $2^{\text {nd }}$ and $3^{\text {rd }}$ years in surgical $(26.9 \pm 1$ and $27.2 \pm 1) \mathrm{kg} / \mathrm{m}^{2}$ and medical 
Table 3: Comparison of clinical and laboratory data of medical group and surgical group before and 3-year after of therapy

\begin{tabular}{|c|c|c|c|}
\hline Variable & $\begin{array}{l}\text { Surgical } \\
(n=33)\end{array}$ & $\begin{array}{l}\text { Medical } \\
(n=64)\end{array}$ & $p$-value \\
\hline Age (years) & $53.6 \pm 4$ & $51.8 \pm 4.8$ & 0.118 \\
\hline Female, $\mathrm{n}(\%)$ & $18(54.5)$ & $32(50)$ & 0.671 \\
\hline Duration of diabetes (years) & $6.8 \pm 2.7$ & $6.3 \pm 2.6$ & 0.479 \\
\hline Baseline SBP $(\mathrm{mmHg})$ & $141.5 \pm 8.1$ & $144.5 \pm 8.1$ & 0.0872 \\
\hline Baseline DBP (mmHg) & $86.4 \pm 5.7$ & $88.7 \pm 5.3$ & 0.0513 \\
\hline $\mathrm{SBP}$ at $3^{\text {rd }}$ year $(\mathrm{mmHg})$ & $127.7 \pm 6.4$ & $130.3 \pm 6.1$ & 0.0534 \\
\hline Diastolic BP at $3^{\text {rd }}$ year $(\mathrm{mmHg})$ & $81.4 \pm 3.5$ & $83 \pm 4.1$ & 0.0591 \\
\hline$\%$ change in systolic BP & $-9.75 \pm 20.99$ & $-9.79 \pm 38.6$ & 0.995 \\
\hline$\%$ change in diastolic BP & $-5.79 \pm 38.6$ & $-6.4 \pm 22.6$ & 0.9220 \\
\hline $\mathrm{BMI}$ at baseline $\left(\mathrm{kg} / \mathrm{m}^{2}\right)$ & $35.7 \pm 1.9$ & $36.2 \pm 1.5$ & 0.291 \\
\hline BMI at $3^{\text {rd }}$ year $\left(\mathrm{kg} / \mathrm{m}^{2}\right)$ & $27.2 \pm 1$ & $33.7 \pm 5$ & 0.000 \\
\hline $\mathrm{BMI} \%$ change & $-23.8 \pm 4.3$ & $-6.8 \pm 15$ & 0.000 \\
\hline $\mathrm{HbA} 1 \mathrm{c}(\%, \mathrm{mmoL} / \mathrm{moL})$ at baseline & $8.9 \pm 0.5(74)$ & $8.8 \pm 0.7(73)$ & 0.139 \\
\hline $\mathrm{HbA} 1 \mathrm{c}(\%, \mathrm{mmoL} / \mathrm{moL})$ at $3^{\text {rd }}$ year & $7.3 \pm 0.3(56)$ & $8.2 \pm 0.4(66)$ & 0.000 \\
\hline HbA1c $\%$ change & $-18.7 \pm 5.4$ & $-6.6 \pm 8.4$ & 0.000 \\
\hline No. of patients decreased diabetic medications & $13(39.4)$ & $28(43.8)$ & 0.681 \\
\hline eGFR at baseline $\left(\mathrm{mL} / \mathrm{min} / 1.73 \mathrm{~m}^{2}\right)$ & $100.3 \pm 12.5$ & $104.5 \pm 12.3$ & 0.170 \\
\hline eGFR at $3^{\text {rd }}$ year $(\mathrm{mL} / \mathrm{min} / 1.73 \mathrm{~m} 2)$ & $102.2 \pm 7.6$ & $103.5 \pm 10.5$ & 0.410 \\
\hline eGFR $\%$ change & $3.4 \pm 15.6$ & $0.5 \pm 15.7$ & 0.537 \\
\hline uACR at baseline $(\mathrm{g} / \mathrm{mg})$ & $11.7 \pm 4.8$ & $13.4 \pm 4.5$ & 0.085 \\
\hline uACR at $3^{\text {rd }} y(\mathrm{~g} / \mathrm{mg})$ & $18.2 \pm 5.9$ & $17.1 \pm 6$ & 0.450 \\
\hline uACR $\%$ change & $86.7 \pm 101.8$ & $42.6 \pm 72.7$ & 0.039 \\
\hline No. of patients developed albuminuria & 3 & 2 & 0.208 \\
\hline
\end{tabular}

groups (33.4 \pm 4.8 and $33.7 \pm 5$ ), sleeve-gastrectomy group had better \% BMI reduction than medical group at the end of the study (Table 3 and Figure 1).

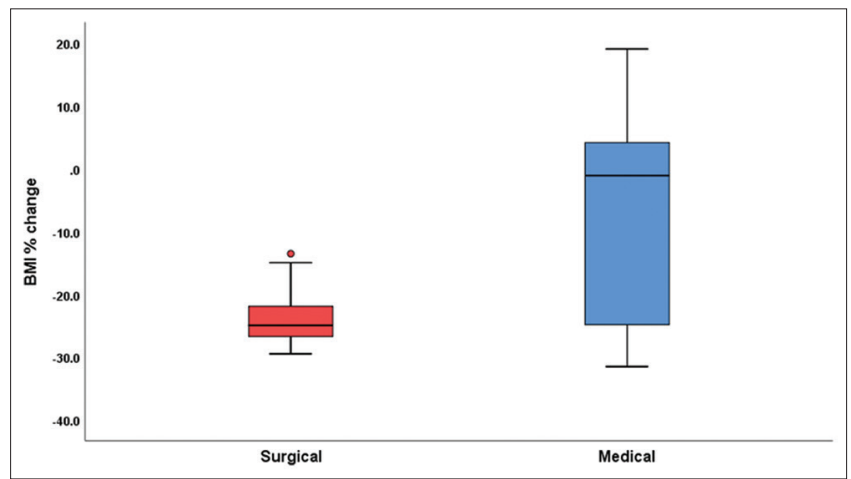

Figure 1: Percentage reduction in BMI in sleeve-gastrectomy group versus medical therapy group. Percentage reduction in BMI in patients undergone sleeve- gastrectomy was significantly higher than the reduction in BMI obtained by medical therapy $(P=0.000)$

Percentage reduction in BMI in patients undergone sleeve-gastrectomy was significantly higher than the reduction in BMI obtained by medical therapy $(p=0.000)$.

The overall glycemic control improved during the 3-year follow-up period and the main reduction in mean $\mathrm{HbA} 1 \mathrm{c}$ was in the $1^{\text {st }}$ year in both medical $8.5 \pm$ $0.6 \%(69.4 \mathrm{mmol} / \mathrm{mol})$ and surgical $6.9 \pm 0.4 \%(51.9$ $\mathrm{mmol} / \mathrm{mol}$ ) groups. Although there was no statistically significant difference in the $\mathrm{HbA} 1 \mathrm{c}$ between surgical and medical group at baseline, sleeve-gastrectomy group had lower mean HbA1c $7.3 \pm 0.3 \%(56.3 \mathrm{mmol} / \mathrm{mol})$ than group of medical therapy $8.2 \pm 0.4 \%(66.1 \mathrm{mmol} /$ $\mathrm{mol}$ ) at the $3^{\text {rd }}$ post-operative year. Furthermore, the mean percentage of $\mathrm{HbA} 1 \mathrm{c}$ reduction among patients underwent sleeve gastrectomy was greater $(-18.7$ $\pm 5.4 \%)$ than among those received medical therapy alone $(-6.6 \pm 8.4 \%)(p=0.0001)$ (Table 3).

The percentage reduction in the number of diabetes medications after bariatric surgery was $(-26$ $\pm 40.5 \%)$ and $(-15.1 \pm 20 \%)$ with medical therapy; the difference was not statistically significant $(p=0.702)$. The percentage of patients who decreased diabetes medications at the end of the study was not different between surgical and medical cases (Table 3 ).

In the beginning of the study, the range of eGFR was $(84-118) \mathrm{mL} / \mathrm{min} / 1.73 \mathrm{~m}^{2}$ in the surgical patient and $(86-120) \mathrm{mL} / \mathrm{min} / 1.73 \mathrm{~m}^{2}$ in the medical subjects. There was no statistically significant difference in mean eGFR between the patients who underwent sleeve-gastrectomy and those who received medical therapy at the baseline (100.3 \pm 12.5 vs. $104.5 \pm 12.3)$ $\mathrm{mL} / \mathrm{min} / 1.73 \mathrm{~m}^{2}$ or at end of the study $(102.2 \pm 7.6 \mathrm{vs}$. $103.5 \pm 10.5) \mathrm{mL} / \mathrm{min} / 1.73 \mathrm{~m}^{2}$. In addition, the mean percentage of change in the eGFR was not statistically significant different among the patients who underwent sleeve-gastrectomy and those received medical therapy alone ( $3.4 \pm 15.6$ and $0.5 \pm 15.7$, respectively) $(p=0.537)$

All patients had normal baseline UACR and at the $3^{\text {rd }}$ year of the study there was no significant difference in the number of patients who developed albuminuria between the medical group and surgical group (two patients in the medical group and three patients in the surgical group). However, there was significant increase in the mean percentage of change in the albuminuria after sleeve gastrectomy than with medical therapy $(86.7 \pm 101.8 \%$ and $42.6 \pm 72.7 \%$, respectively) (Table 3 and Figure 2).Percentage change in $\mathrm{UACR}$ in patients undergone sleeve-gastrectomy was significantly higher than \% change in UACR in medical group $(p=0.039)$.

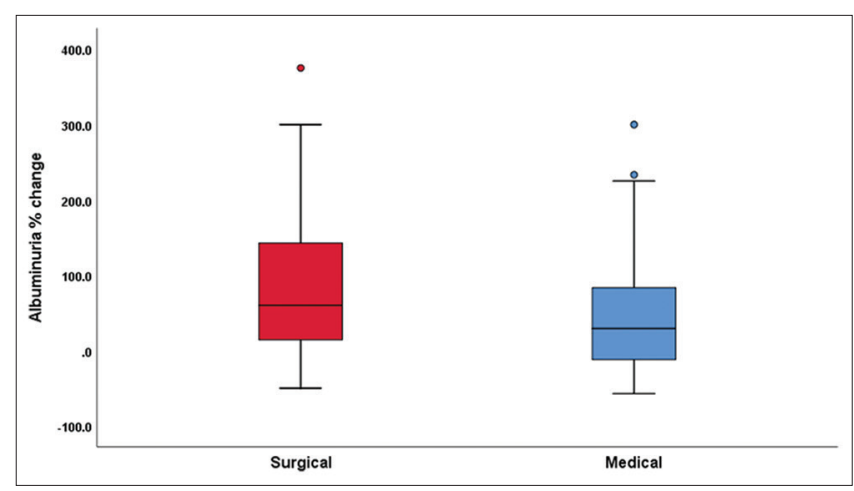

Figure 2: Percentage change in urine albumin-to-creatinine ratio (UACR) in sleeve-gastrectomy group versus medical therapy group. Percentage change in urine albumin-to-creatinine ratio (UACR) in patients undergone sleeve-gastrectomy was significantly higher than $\%$ change in $U A C R$ in medical group $(P=0.039)$

\section{Discussion}

This prospective study was aiming to compare the effect of bariatric surgery versus intensive medical therapy on prevention of microalbuminuria in patients with T2DM. We found that after 3-year follow-up, 
sleeve-gastrectomy was not superior to medical treatment on prevention of microalbuminuria in obese patients with T2DM.

Most of the previous studies have shown that bariatric surgery has significantly favorable effect on albuminuria in patients with T2DM and DKD [14], [18]. For example, one study showed almost $80 \%$ improvements in albuminuria after bariatric surgery in patients with T2DM and diabetic nephropathy [18]. Another study showed nearly $70 \%$ reduction in diabetic nephropathy in patients with T2DM and preoperative micro- and macroalbuminuria [14]. Only one study compared between the effect of medical and surgical therapy of diabetic patients with diabetic nephropathy that found significant reduction in albuminuria in surgical group while the medical group had no changes at 1-year follow-up [19]. However, none of these studies investigated the effect of metabolic surgery compared to the intensive medical therapy on prevention of DKD in patients with T2DM and normoalbuminuria.

The favorable effects of metabolic surgery are well known, bariatric surgery is associated with remission or at least improvement of diabetes and many of diabetes-related comorbidities such as hypertension and dyslipidemia [20], [21]. The mechanisms of improvement in albuminuria after bariatric surgery remain unclear. Obesity per se is associated with low-grade inflammation, hormonal changes in the renin angiotensin and sympathetic nervous systems leading to hemodynamic, structural, and functional changes of the glomeruli and albuminuria [22]. In addition, metabolic syndrome, diabetes and hypertension, well established as major causes of chronic kidney disease, are closely associated with obesity. The positive effect of bariatric surgery on albuminuria may be mediated by the improvement of several risk factors such as diabetes and hypertension.

Although, in our study, the surgical patients achieved lower $\mathrm{BMI}$ and $\mathrm{HbA} 1 \mathrm{c}$ than medical group, the prevalence of albuminuria in the medical group at 3-year follow-up was not different from the surgical group. The correlation between the degree of obesity and the degree of albuminuria in obese patient is not constant across the different studies [23], [24]. While some researchers reported significant correlation between BMI and the level of albuminuria [23], [25] others failed to confirm this association [26]. The previous study in subjects without diabetes reported that the prevalence of microalbuminuria was associated with low BMI in men and was not associated with waist circumference in either men or women [24]. Moreover, a study of patients with diabetes found that the incidence of microalbuminuria had linear relation with age as well as with increased duration of diabetes mellitus but not with the BMI [27]. In addition, metabolic parameters rather than BMI are predictors of an increased incidence of albuminuria among obese individuals [30]. All of these can explain the same occurrence of albuminuria in both medical and surgical groups as both groups had similar age, duration of diabetes, and blood pressure levels which are key players in the development of albuminuria in patients with diabetes [24], [26].

Obesity and diabetes are characterized by a varying degree of resistance to the physiological effect of insulin. Recent observations suggest that insulin signaling in podocytes, cells having a pivotal role in kidney filtration, and contributes to albuminuria [28]. A modest weight loss of $5-10 \%$ of original weight can increase insulin sensitivity and improve many of metabolic parameters [29]. In the current study, although surgical patients achieved greater weight reduction than medical group, the \% change in BMI in medical group exceeded $5 \%$ and this could explain why albuminuria prevalence did not differ between medical and surgical group in spite higher $\mathrm{HbA} 1 \mathrm{c}$ in the medical group. The previous study reported that the baseline uACR was a strong predictor in determining microalbuminuria and the baseline UACR had demonstrated high impacts on subjects with both low and high HbA1c baseline levels furthermore, $\mathrm{HbA} 1 \mathrm{c}$ level demonstrated impact on patients with high-normal baseline UACR, but the $\mathrm{HbA} 1 \mathrm{c}$ level had shown no significance for patients with low-normal albuminuria [30]. In the current study, mean uACR at the baseline was $<15 \mathrm{mg} / \mathrm{g}$ in both medical and surgical cases.

This study has many strengths including first, it was a prospective study. Second, the duration of follow-up was 3-years. Third, the patients had 100\% follow-up rate. Finally, compared to the previous studies that lack control group, we have medical control group that had similar age, gender, baseline $\mathrm{BMI}$, and $\mathrm{HbA} 1 \mathrm{c}$ that might influence the development of albuminuria. However, in this study, the surgical group underwent one bariatric procedure, which was sleeve gastrectomy, compared to the previous studies that included multiple surgical modalities. The effectiveness of the different procedures is not the same [31], so we cannot generalize the renal outcome of one bariatric procedure to the other modalities and further research is needed to compare renal outcomes of different bariatric surgeries.

\section{Conclusion}

Sleeve-gastrectomy could reduce the weight and improve glycemic control in obese patients with T2DM compared to medical therapy. However, in this study, sleeve gastrectomy was not superior to intensive medical treatment in prevention of microalbuminuria in this group of patients at 3-years follow-up. 


\section{Acknowledgment}

All authors acknowledge their gratitude to the staff members of diabetes and endocrine clinic and surgery clinic for their help and support.

\section{References}

1. Whiting DR, Guariguata L, Weil C, Shaw J. IDF diabetes atlas: Global estimates of the prevalence of diabetes for 2011 and 2030. Diabetes Res Clin Pract. 2011;94(3):311-21. https://doi. org/10.1016/j.diabres.2011.10.029

PMid:22079683

2. Israel Defense Forces. IDF Diabetes Atlas. $5^{\text {th }}$ ed. Brussels, Belgium: Israel Defense Forces; 2013.

3. Molitch ME, DeFronzo RA, Franz MJ, Keane WF, Mogensen CE, Parving $\mathrm{HH}$, et al. Nephropathy in diabetes. Diabetes Care. 2004;27(Suppl 1):S79-83.

PMid:14693934

4. Romagnani P, Remuzzi G, Glassock R, Levin A, Jager KJ, Tonelli M, et al. Chronic kidney disease. Nat Rev Dis Primers. 2017;3:17088. https://doi.org/10.1038/nrdp.2017.88 PMid:29168475

5. González-Muniesa P, Mártinez-González MA, Hu FB, Després JP, Matsuzawa Y, Loos RJF, et al. Obesity. Nat Rev Dis Primers. 2017;3:17034. https://doi.org/10.1038/nrdp.2017.34 PMid:28617414

6. Garofalo C, Borrelli S, Minutolo R, Chiodini P, De Nicola L, Conte G. A systematic review and meta-analysis suggests obesity predicts onset of chronic kidney disease in the general population. Kidney Int. 2017;91(5):1224-35. https://doi. org/10.1016/j.kint.2016.12.013

PMid:28187985

7. Rossi MC, Nicolucci A, Pellegrini F, Comaschi M, Ceriello $\mathrm{A}$, Cucinotta $\mathrm{D}$, et al. Obesity and changes in urine albumin/ creatinine ratio in patients with Type 2 diabetes: the DEMAND study. Nutr Metab Cardiovasc Dis. 2010;20(2):110-6. https://doi. org/10.1016/j.numecd.2009.02.013

PMid:19447588

8. Bayliss G, Weinrauch LA, D'Elia JA. Pathophysiology of obesityrelated renal dysfunction contributes to diabetic nephropathy. Curr Diab Rep. 2012;12(4):440-6. https://doi.org/10.1007/ s11892-012-0288-1

PMid:22638939

9. Wong MG, Perkovic V, Chalmers J, Woodward M, Li Q, Cooper ME, et al. Long-term benefits of intensive glucose control for preventing end-stage kidney disease: Advance-on. Diabetes Care. 2016;39(5):694-700. https://doi.org/10.2337/ dc15-2322

PMid:27006512

10. Morales E, Praga M. The effect of weight loss in obesity and chronic kidney disease. Curr Hypertens Rep. 2012;14(2):170-6 https://doi.org/10.1007/s11906-012-0247-x PMid:22258314.

11. Tirosh A, Golan R, Harman-Boehm I, Henkin Y, Schwarzfuchs $D$, Rudich $A$, et al. Renal function following three distinct weight loss dietary strategies during 2 years of a randomized controlled trial. Diabetes Care. 2013;36(8):2225-32. https://doi. org/10.2337/dc12-1846

\section{PMid:23690533}

12. Heneghan HM, Cetin D, Navaneethan SD, Orzech $N$, Brethauer SA, Schauer PR. Effects of bariatric surgery on diabetic nephropathy after 5 years of follow-up. Surg Obes Relat Dis. 2013;9(1):7-14. https://doi.org/10.1016/j.soard.2012.08.016 PMid:23211651

13. Afshinnia F, Wilt TJ, Duval S, Esmaeili A, Ibrahim HN. Weight loss and proteinuria systematic review of clinical trials and comparative cohorts. Nephrol Dial Transplant. 2010;25(4):117383. https://doi.org/10.1093/ndt/gfp640 PMid: 19945950

14. Chao AT, Fang SC, Lam BC, Cheng AK, Low SK, Chi LS Effect of bariatric surgery on diabetic nephropathy in obese Type 2 diabetes patients in a retrospective 2-year study: A local pilot. Diab Vasc Dis Res. 2018;15(2):139-44. https://doi. org/10.1177/1479164117742315 PMid:29153006

15. Nathan DM, Buse JB, Davidson MB, Ferrannini E, Holman RR, Sherwin $\mathrm{R}$, et al. Medical management of hyperglycemia in Type 2 diabetes: A consensus algorithm for the initiation and adjustment of therapy: A consensus statement of the American diabetes association and the European association for the study of diabetes. Diabetes Care. 2009;32(1):193-203. https://doi. org/10.2337/dc08-9025

PMid: 18945920

16. American Diabetes Association. Standards of medical care in diabetes 2011. Diabetes Care. 2019;24:Suppl 1:S46-71. https:// doi.org/10.2337/dc19-s005

17. Levey AS, Coresh J, Greene T, Stevens LA, Zhang YL, Hendriksen $\mathrm{S}$, et al. Using standardized serum creatinine values in the modification of diet in renal disease study equation for estimating glomerular filtration rate. Ann Intern Med. 2006;145(4):247-54. https://doi. org/10.7326/0003-4819-145-4-200608150-00004 PMid: 16908915

18. Young L, Hanipah ZN, Brethauer SA, Schauer PR, Aminian A Long-term impact of bariatric surgery in diabetic nephropathy. Surg Endosc. 2019;33(5):1654-60. https://doi.org/10.1007/ s00464-018-6458-8

PMid:30251143

19. Miras AD, Chuah LL, Khalil N, Nicotra A, Vusirikala A, Baqai N et al. Type 2 diabetes mellitus and microvascular complications 1 year after Roux-en-Y gastric bypass: A case-control study. Diabetologia. 2015;58(7):1443-7. https://doi.org/10.1007/ s00125-015-3595-7

PMid:25893730

20. Schauer PR, Bhatt DL, Kirwan JP, Wolski K, Aminian A Brethauer SA, et al. Bariatric surgery versus intensive medical therapy for diabetes 5-year outcomes. N Engl J Med. 2017;376(7):641-51. https://doi.org/10.1056/nejmoa1600869 PMid:28199805

21. Cohen RV, Pinheiro JC, Schiavon CA, Salles JE, Wajchenberg BL, Cummings DE. Effects of gastric bypass surgery in patients with Type 2 diabetes and only mild obesity. Diabetes Care. 2012;35(7):1420-8. https://doi.org/10.2337/dc11-2289 PMid:22723580

22. Eknoyan G. Obesity and chronic kidney disease. Nefrologia. 2011;31(4):397-403.

PMid:21623393

23. Liu X, Liu Y, Chen Y, Li Y, Shao X, Liang Y, et al. Body mass index (BMI) is associated with microalbuminuria in Chinese hypertensive patients. Int $\mathrm{J}$ Environ Res Public Health. 2015;12(2):1998-2008. https://doi.org/10.3390/ijerph120201998 PMid:25674785

24. Seo WJ, Lee GM, Hwang JH, Lee MN, Kang HC. Association 
between body mass index, waist circumference and prevalence of microalbuminuria in Korean adults of age 30 years and older without diabetes, hypertension, renal failure, or overt proteinuria: The 2013 Korean national health and nutrition examination survey. Korean J Fam Med. 2016;37(1):57-63. https://doi.org/10.4082/kjfm.2016.37.1.57

PMid:26885324

25. Toto RD, Greene T, Hebert LA, Hiremath L, Lea JP, Lewis JB et al. Relationship between body mass index and proteinuria in hypertensive nephrosclerosis: Results from the African American study of kidney disease and hypertension (AASK) cohort. Am J Kidney Dis. 2010;56(5):896-906. https://doi. org/10.1053/j.ajkd.2010.05.016

PMid:20801567

26. Chowta NK, Pant P, Chowta MN. Microalbuminuria in diabetes mellitus: Association with age, sex, weight, and creatinine clearance. Indian J Nephrol. 2009;19(2):53-6. https://doi. org/10.4103/0971-4065.53322

PMid:20368924

27. Carlsson LM, Romeo S, Jacobson P, Burza MA, Maglio C, Sjöholm K, et al. The incidence of albuminuria after bariatric surgery and usual care in Swedish obese subjects (SOS):
A prospective controlled intervention trial. Int $\mathrm{J}$ Obes (Lond) 2015;39(1):169-75. https://doi.org/10.1038/ijo.2014.72 PMid:24798033

28. Coward RJ, Saleem MA. Podocytes as a target of insulin. Curr Diabetes Rev. 2011;7(1):22-7.

PMid:21067503

29. Goldstein DJ. Beneficial health effects of modest weight loss. Int J Obes Relat Metab Disord. 1992;16(6):397-415

PMID: 1322866

30. Chen WZ, Hung CC, Wen YW, Ning HC, Gau BR, Huang YY Effect of glycemic control on microalbuminuria development among Type 2 diabetes with high-normal albuminuria. Ren Fail. 2014;36(2):171-5. https://doi.org/10.3109/08860 22x.2013.832312

PMid:24028605.

31. Guerreiro V, Neves JS, Salazar D, Ferreira MJ, Oliveira SC Souteiro $\mathrm{P}$, et al. Long-term weight loss and metabolic syndrome remission after bariatric surgery: The effect of sex, age, metabolic parameters and surgical technique a 4-year follow-up study. Obes Facts. 2019;12(6):639-52. https://doi. org/10.1159/000503753

PMid:31747662 